\title{
INCREASED FLEXIBILITY OF TURBO- COMPRESSORS IN NATURAL GAS TRANSMISSION THROUGH DIRECT SURGE CONTROL
}

\author{
Annual Technical Progress Report \\ October 2002 - September 2003
}

\author{
Prepared for \\ U.S. Department of Energy \\ National Energy Technology Laboratory \\ 3610 Collins Ferry Road \\ P.O. Box 880 \\ Morgantown, WV 26507-0880
}

December 2003

SwRI ${ }^{\circledR}$ Project No. 18.04990

DOE Award No. DE-FC26-01NT41163

\section{Prepared by}

Robert J. McKee

Danny M. Deffenbaugh

Southwest Research Institute ${ }^{\circledR}$

Mechanical and Materials Engineering Division

6220 Culebra Road

San Antonio, TX 78238-5166

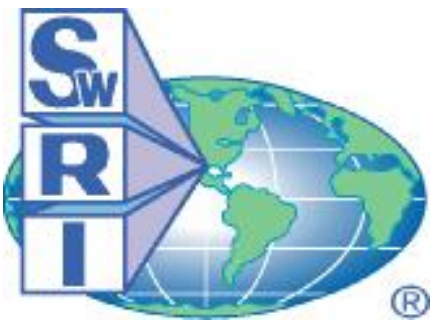

SOUTHWEST RESEARCH INSTITUTE ${ }^{\circledR}$ 


\title{
INCREASED FLEXIBILITY OF TURBO- COMPRESSORS IN NATURAL GAS TRANSMISSION THROUGH DIRECT SURGE CONTROL
}

\section{Annual Technical Progress Report October 2002 - September 2003}

\author{
Prepared for \\ U.S. Department of Energy \\ National Energy Technology Laboratory \\ 3610 Collins Ferry Road \\ P.O. Box 880 \\ Morgantown, WV 26507-0880
}

December 2003

SwRI ${ }^{\circledR}$ Project No. 18.04990

DOE Award No. DE-FC26-01NT41163

\section{Prepared by}

Robert J. McKee

Danny M. Deffenbaugh

Southwest Research Institute ${ }^{\circledR}$

Mechanical and Materials Engineering Division

6220 Culebra Road

San Antonio, TX 78238-5166

Approved:

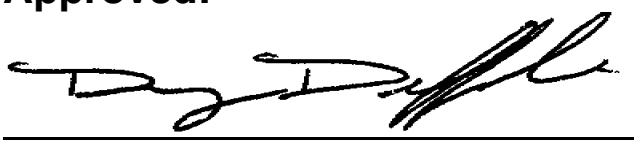

Danny M. Deffenbaugh, Director

Mechanical and Fluids Engineering Department 


\section{DISCLAIMER}

This report was prepared as an account of work sponsored by an agency of the United States Government. Neither the United States nor any agency thereof, nor any of their employees, makes any warranty, express or implied, or assumes any legal liability or responsibility for the accuracy, completeness, or usefulness of any information, apparatus, product, or process disclosed, or represents that its use would not infringe privately owned rights. Reference herein to any specific commercial product, process, or service by trade name, trademark, manufacturer, or otherwise does not necessarily constitute or imply its endorsement, recommendation, or favoring by the United States Government or any agency thereof. The views and opinions of authors expressed herein do not necessarily state or reflect those of the United States Government or any agency thereof. 


\section{ABSTRACT}

This annual progress report describes the second year's technical progress in a three-year program. This report summarizes what is known about internal flows as surge precursors in centrifugal compressors and focuses on accessing factors that affect pre-surge detection. An attempt is made in this analysis to identify and quantify factors concerning compressor design and operations that affect the detection of pre-surge conditions. This progress report presents results from recent laboratory tests conducted during the course of this second year. This project is co-funded by the Gas Machinery Research Council (GMRC) and by Siemens Energy and Automation (Siemens). The most recently available measured pre-surge internal flow data is parameterized to help identify factors that affect the indications that a compressor is approaching surge. Theoretical arguments are applied to access the factors that influence surge precursors and surge initiation in different centrifugal compressors. This work is considered a step in accessing the factors that affect the success or limitations of pre-surge detection in natural gas pipeline compressors. 


\section{TABLE OF CONTENTS}

Section $\quad$ Page

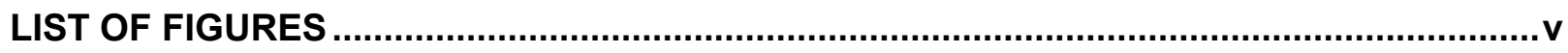

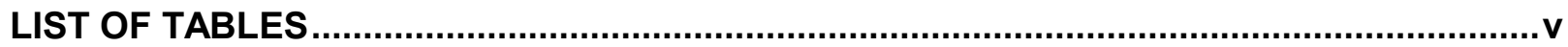

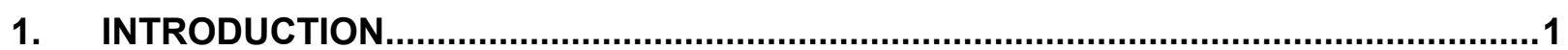

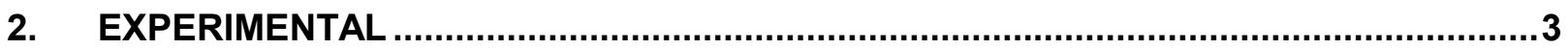

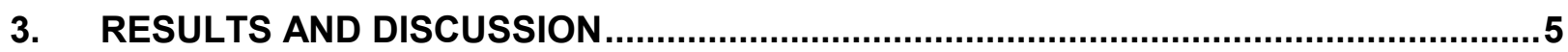

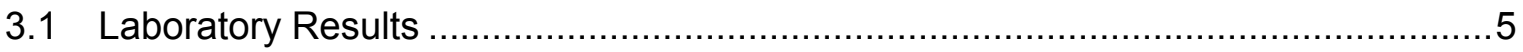

3.2 Theories and Factors That Affect Surge PreCursors .......................................

3.3 Future Testing and Expected Benefits................................................... 11

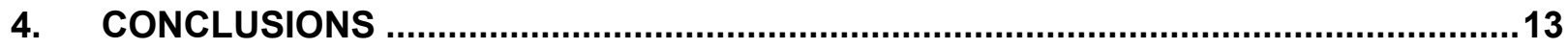

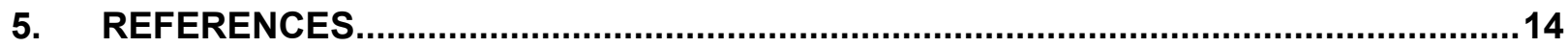




\section{LIST OF FIGURES}

Figure

Page

Figure 1. A Typical Centrifugal Compressor Operating Map Showing a Surge Line and a Current Technology Surge Control Line.

Figure 2. Pre-Surge Change in Impeller Inlet Flow along the Outer Wall of a Small Laboratory Compressor during Early GMRC Research.

Figure 3. Axial and Tangential Strain Changes with Scaled Flow for Low-Speed Operation Leading Up to Surge.

Figure 4. Axial and Tangential Strain Changes with Scaled Flow for High-Speed Operation Leading Up to Surge.

Figure 5. Plot of Axial Strain Changes as a Function of Flow Coefficient for Three Different Tests.

Figure 6. Compressor Map for the Second Laboratory Compressor Showing the Operating Range According to the Conventional Surge Line and Using a Surge Probe.

Figure 7. Diagram of Flow Vectors at a Normal Flow Condition with the Drag Probe Location Shown.

Figure 8. Diagram of Flow Vectors at a Low-Flow Condition Showing the First Recirculation.

Figure 9. Diagram of Flow Vectors at a Near-Surge Condition Showing Recirculation Just at the Drag Probe.

Figure 10. Diagram of Flow Vectors at a Surge Flow Condition Showing a Large Recirculation Zone.

Figure 11. Photographs of a Small Typical Laboratory Surge Sensor Drag Probe and the Installation of Two Surge Sensor Probes in Field Compressor Ready for Testing.

\section{LIST OF TABLES}

$\underline{\text { Table }}$

Page

Table 1. Nondimensional Parameter of Flow Coefficient and Probe Location for Test Compressors. 


\section{INTRODUCTION}

This research project will develop the next generation surge controller for gas transmission compressors. The objectives are to develop an internal surge control sensor and an associated surge control system that will allow reduced surge margins, increase the range and flexibility of operation, and safely minimize the energy and cost of avoiding surge in pipeline centrifugal compressors. If the factors that affect drag probe signals can be quantified, then surge detection signals due to this method can be understood, and the maximum benefit of the internal direct surge control method can be obtained.

Centrifugal compressors constitute a significant portion of the compression equipment used along North America's pipelines, and because of their economic advantages will continue to be installed as a significant part of the natural gas infrastructure. A typical performance map for a pipeline centrifugal compressor, which shows the pressure increase as head rise as a function of inlet volumetric flow for a range of compressor speeds, is shown in Figure 1. This compressor map indicates that there are limits on the operating range of such a compressor. The limit for low-flow operations is set by a flow instability known as surge. The exact location on the compressor map at which surge occurs is not normally known and, as a result, a surge control line is established with a significant margin above the flow at which surge is expected to occur. A typical surge margin is usually 10 percent or more of the design flow.

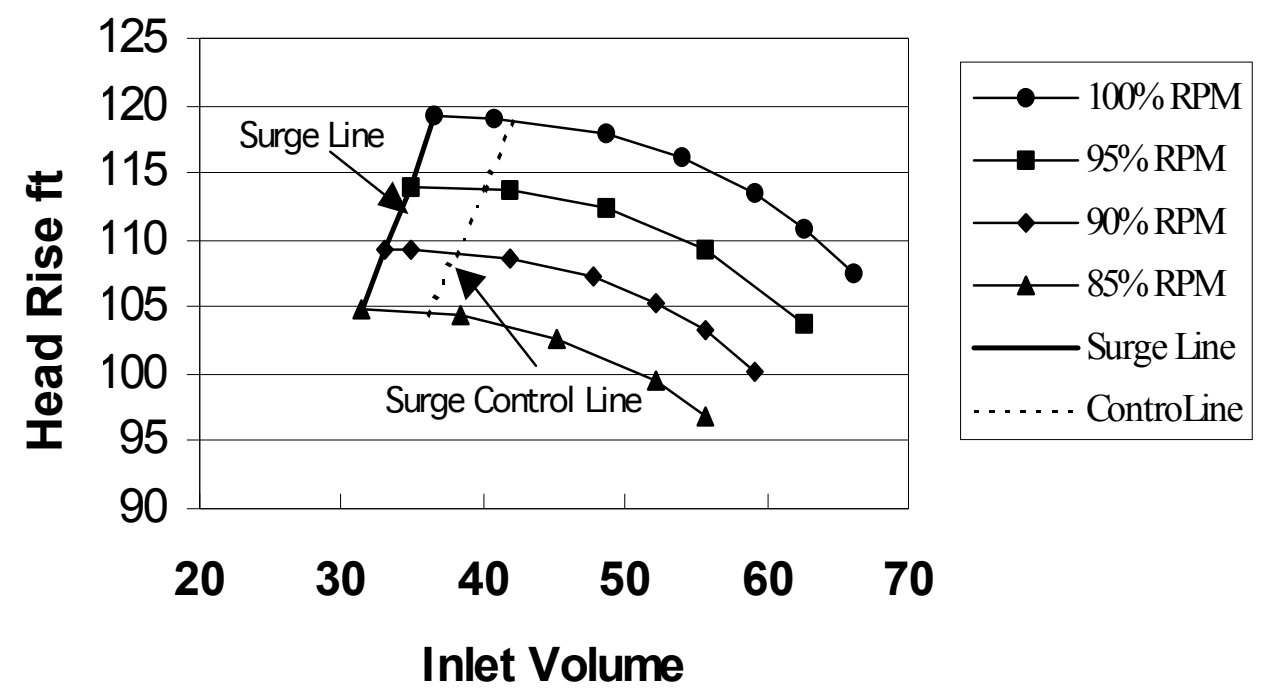

\section{Figure 1. A Typical Centrifugal Compressor Operating Map Showing a Surge Line and a Current Technology Surge Control Line.}

Surge is a global instability in a centrifugal compressor's flow that results in a complete breakdown and reversal of flow through the compressor. Surge occurs just below the minimum flow that the compressor can sustain against the existing suction to discharge pressure rise (head). When surge occurs, both flow rate and head decrease rapidly and gas flows backward within the compressor. Surge is a source of large dynamic forces applied to the compressor 
elements and, hence, a flow phenomena that must be avoided. Surge avoidance is essential for pipeline compressors and is normally achieved by recycling gas around the compressor to maintain a flow no less than the surge control flow rate. External measurements of head and speed are normally used to maintain the operating flow rate above the surge control line. Although the operating point can be maintained by recycling flow, recycling flow around compressors waste energy and can be extremely inefficient. If the physical approach of surge can be detected, then centrifugal compressors can be operated closer to surge and without recycling as much flow. The current surge avoidance and control methods result in recycle valves being used extensively and being opened well before the compressor is actually in danger of reaching surge. The purpose of the current direct surge control effort, using measurements that are internal to the compressor, is to reduce surge margins, use less recycle flow during operations, and reduce wasted fuel and operating costs. 


\section{EXPERIMENTAL}

In the early 1980's, the Gas Machinery Research Council (GMRC) funded research at Southwest Research Institute ${ }^{\circledR}$ to study the causes and processes involved in surge. As a part of this early GMRC research, the inlet area of a small laboratory compressor was instrumented for flow direction and magnitude and for temperature changes. During these tests, the system flow rate was slowly reduced until surge occurred. The most significant changes observed, as this small compressor approached surge, was a reduction in magnitude of velocity in the outer diameter portion of the impeller inlet. This reduction in local flow was significantly greater than the reduction in average velocity, and became negative (flow away from the impeller) close to the surge condition. As flow rate is reduced and the surge limit is approached, flow in the outer part of the impeller inlet reverses and flows out from the impeller, while the bulk flow is still positive towards the impeller. This outer ring of the inlet flow field also develops a tangential component in the direction of the impeller rotation as flow rate is reduced. Figure 2 is a plot of the inlet flow in the direction towards the impeller measured with a bi-directional pitot type probe along the outer wall of the inlet passage, and shows that the flow along the outer wall reduces rapidly, reaches zero, and begins to flow backwards as surge is approached. The data shows that the flow recirculation occurred only in the outer diameter area of the impeller inlet. The temperature of the gas in the outer diameter area was observed to increase during the recirculation. The signal in Figure 2 would be useful as a surge avoidance and control signal if this change can be measured in field compressors. The development of a recirculating flow pattern at the inlet of a centrifugal compressor impeller is an indication of approaching surge.

A surge sensor to be permanently located immediately in front of a centrifugal impeller needs to be rugged and yet sufficiently sensitive to detect small changes in the local flows. The probe must also be compatible with the compressor environment, manufacturable, and reasonably easy to install. In order to avoid unproven technologies, the type of sensor chosen as a rugged and reliable surge flow pattern detector was a drag probe. A drag probe consists of a bluff body located in the flow field with strain gauges mounted on a beam or flexible element, which supports the drag body and senses the flow-induced forces on the probe. A design method to size drag probes for any selected compressor has been developed and drag probes have been designed, built, and bench-tested for use in several different compressors. As part of the current research effort, tests have been performed in two different laboratory compressors. The results from the first laboratory compressor were summarized in last year's Technical Progress Report ${ }^{1}$. The entire body of work was presented at the Gas Machinery Conference in October $2003^{2}$. 


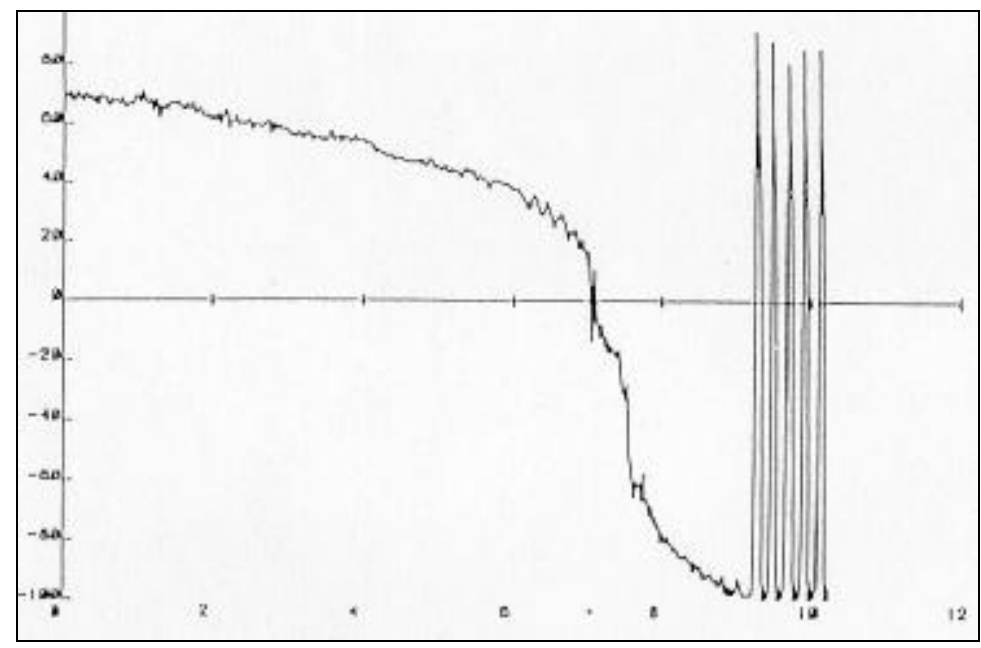

Figure 2. Pre-Surge Change in Impeller Inlet Flow along the Outer Wall of a Small Laboratory Compressor during Early GMRC Research. 


\section{RESULTS AND DISCUSSION}

\subsection{LABORATORY RESULTS}

The laboratory compressor used for this year's testing was smaller in physical size than the unit used in last year's tests but operated at somewhat higher speeds with a higher flow rate and a similar horsepower. This laboratory compressor has a more open and larger inlet passage and is more like pipeline compressors. The results of a low-speed test showing the axial and tangential strain with an indication of the decreasing flow is shown in Figure 3. During this test, as flow decreased towards the surge region, the axial strain increased at first and then rapidly decreased and became negative as the tangential strain increased from near zero to significantly positive values. Both the axial and tangential strain levels started to change less rapidly just before surge was reached. The results of a similar test at a higher speed are shown in Figure 4, where the increase in axial strain before the rapid decrease is clearly indicated and the change in the tangential strain is also clearly observed. These same changes in strain as flow decreases occur either slowly with pauses at stable flow conditions or continuously over a short (twominute) time frame. The changes in strain signals at the highest speeds tested are remarkably similar in characteristic to the other speed results as surge approaches. The difference between the flow coefficient at which indications of pre-surge were seen and the flow conditions at which surge occurred for a typical moderate speed test of this second laboratory compressor was 19.6 percent of the design flow. A signal as repeatable as observed during this laboratory testing can be used as an improved surge control and will, as indicated by the data, provide a significantly wider useable range of operation for the compressor.

The flow coefficient, which is the ratio of the inlet volumetric flow to the impeller speed, is a measure of the capacity of the machine per unit speed. Specifically, for this report, the flow coefficient is the inlet volumetric flow rate divided by the compressor speed and the cube of the inlet radius in order to obtain a nondimensional number. At the design flow and speed, the flow coefficient indicates the size of the compressor. At off design flow for a particular compressor, the flow coefficient indicates the amount of flow per unit speed by which the operating capacity of the machine has been reduced.

In this experimental data, the flow coefficient appears to control the conditions at which the surge precursor and surge occur, as shown in Figure 5, which is a plot of the axial strain signal as a function of flow coefficient for three different test speeds. As flow decreases towards surge, the flow coefficient decreases and the axial strain signal moves to the left in Figure 5. While the strain is positive, it is safe to operate the compressor in that condition; however, as the strain level drops rapidly and becomes negative, further flow reduction should be prevented in order to avoid surge. 


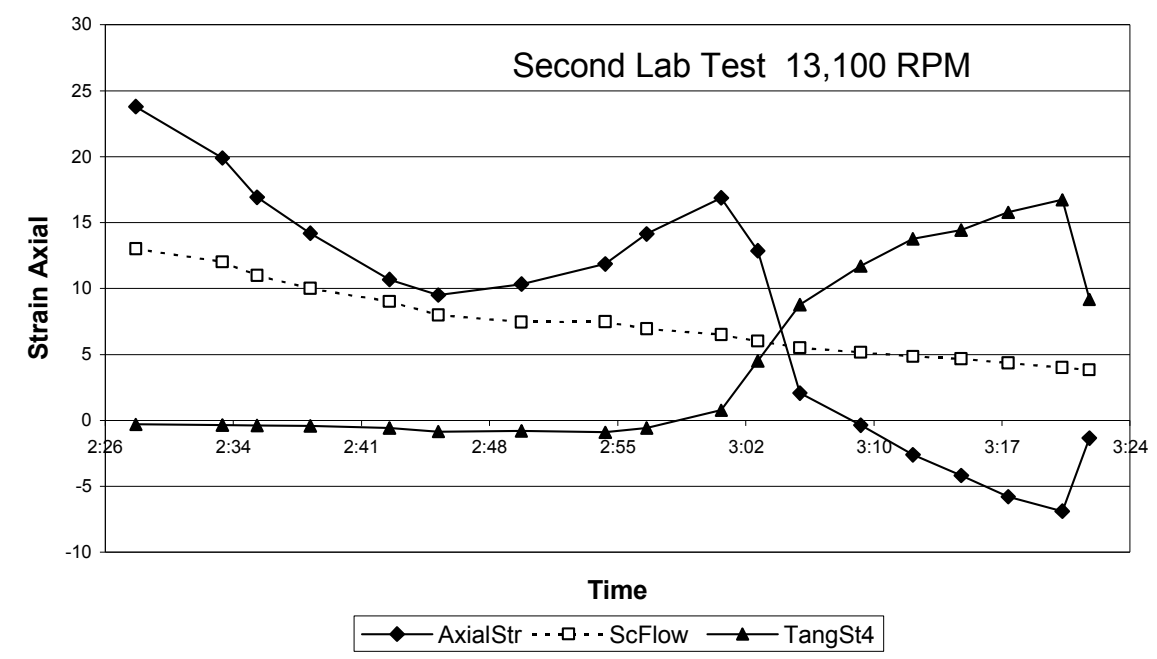

Figure 3. Axial and Tangential Strain Changes with Scaled Flow for Low-Speed Operation Leading Up to Surge.

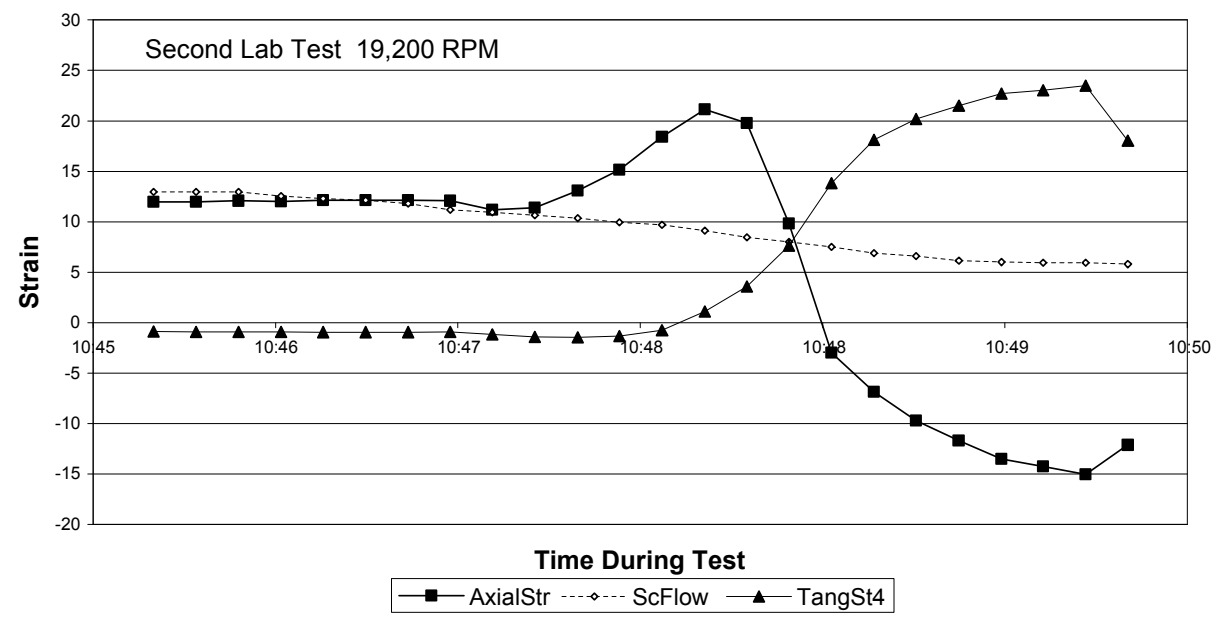

Figure 4. Axial and Tangential Strain Changes with Scaled Flow for High-Speed Operation Leading Up to Surge.

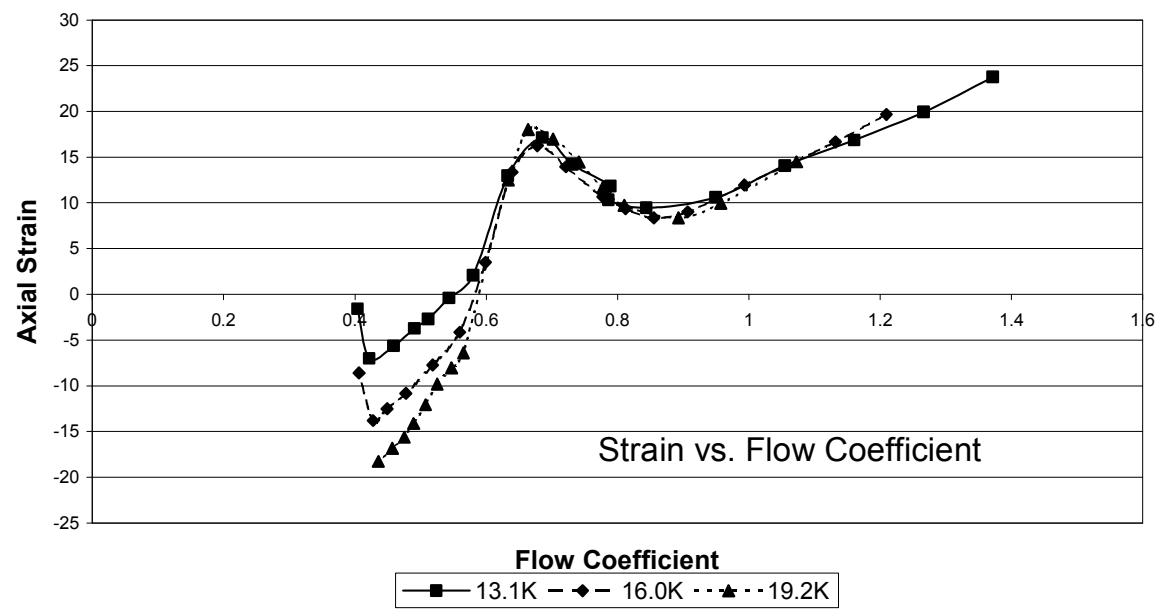

Figure 5. Plot of Axial Strain Changes as a Function of Flow Coefficient for Three Different Tests. 
The results for the second year's laboratory test of pre-surge detection are shown on a compressor map in Figure 6, where an estimate surge line provided by the manufacturer is included. Using the surge detection probe and well controlled laboratory condition, a significant increase in operating range was achieved. The term turndown is the percent of the design flow rate by which the flow through a centrifugal compressor can be reduced before surge is reached. The turndown for the second laboratory compressor based on the manufacturer ${ }^{1}$ estimates was 47 percent. The turndown based on the surge detection probes was approximately 68 percent, which is a 21 percent increase in the operating flow range. Although this is a very large increase in operating range, the increase for pipeline compressors where the test conditions are not as stable and the probe signal may not be as strong may not be as large. Only further development and testing will be able to quantify the achievable increase in operating range.

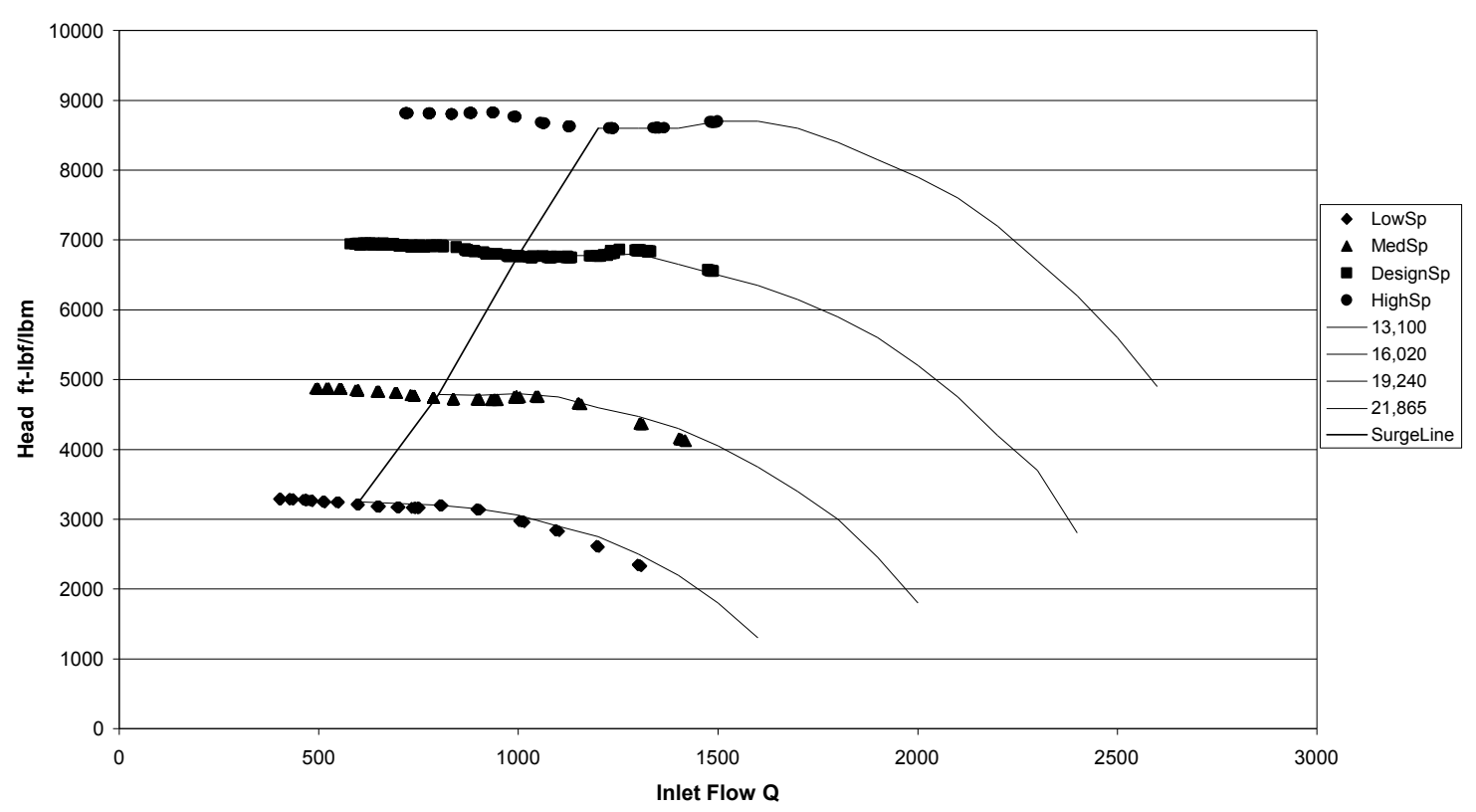

Figure 6. Compressor Map for the Second Laboratory Compressor Showing the Operating Range According to the Conventional Surge Line and Using a Surge Probe.

Returning to the strain data as a function of flow coefficient, the shape of the axial strain curves seen in these tests is dependent on the position of the probe relative to the impeller inlet. A series of diagrams showing flow velocity vectors in the area of the drag probe at various flow levels are shown in Figures 7 through 10. At a normal flow rate, the velocity vectors pass over the drag probe while traveling towards the impeller and the strain is positive. At the first lowflow condition, a small recirculation zone develops close to the impeller and the outer wall, but does not reach the drag probe. In the area of the drag probe at this low-flow condition, the velocity that is approaching the recirculation must accelerate to pass over the small recirculating flow cell, and it is this accelerated flow acting on the drag probe that increases the axial strain, even when the overall flow is decreasing. As the flow is lowered further to the near-surge condition, the recirculation cell reaches the drag probe, the rapid drop in axial strain occurs, and the increase in tangential strain starts because it is the recirculating flow cell that contains the three-dimensional flow patterns including the tangential flow component. Finally, just before 
surge, the recirculating flow cell becomes so large that flow is acting in the reverse direction on the drag probe (if it is close enough to the impeller), so that the axial strain is negative and the tangential strain is large. At this large recirculating flow condition, surge is imminent.

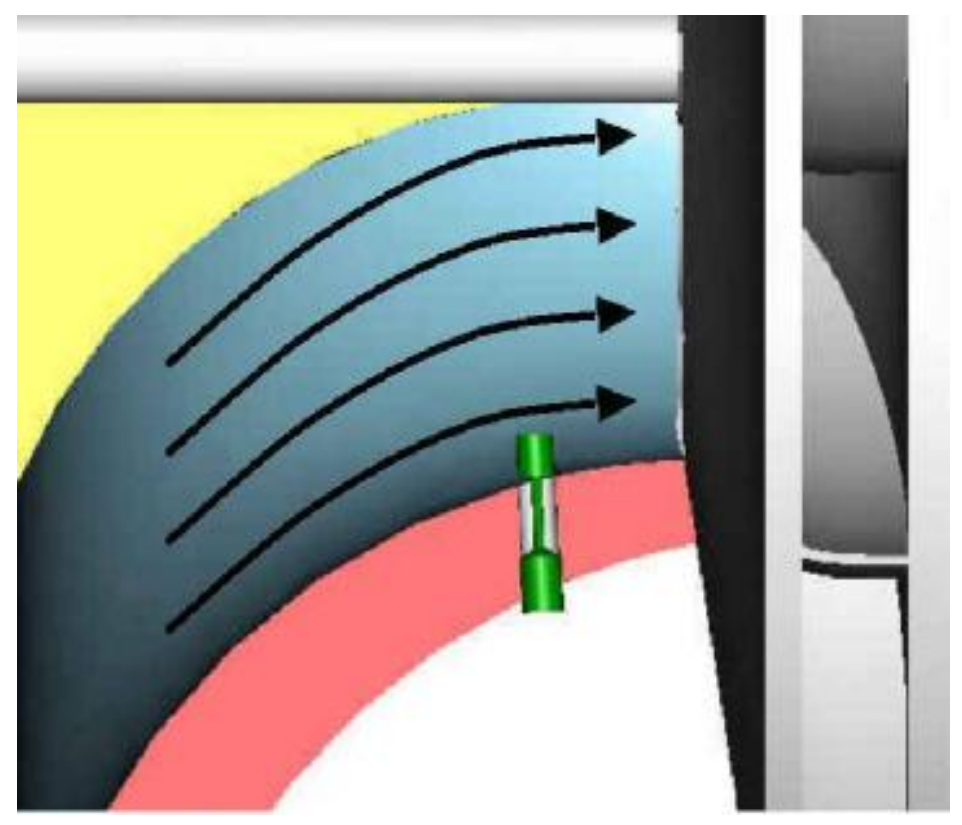

Figure 7. Diagram of Flow Vectors at a Normal Flow Condition with the Drag Probe Location Shown.

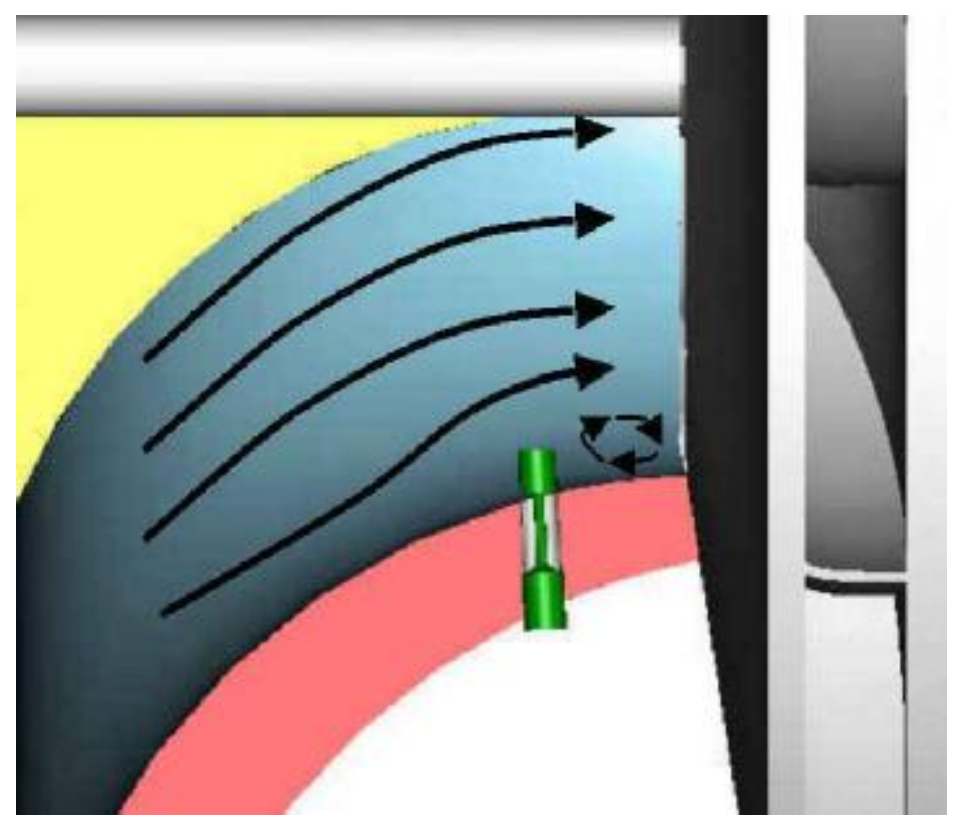

Figure 8. Diagram of Flow Vectors at a Low-Flow Condition Showing the First Recirculation. 


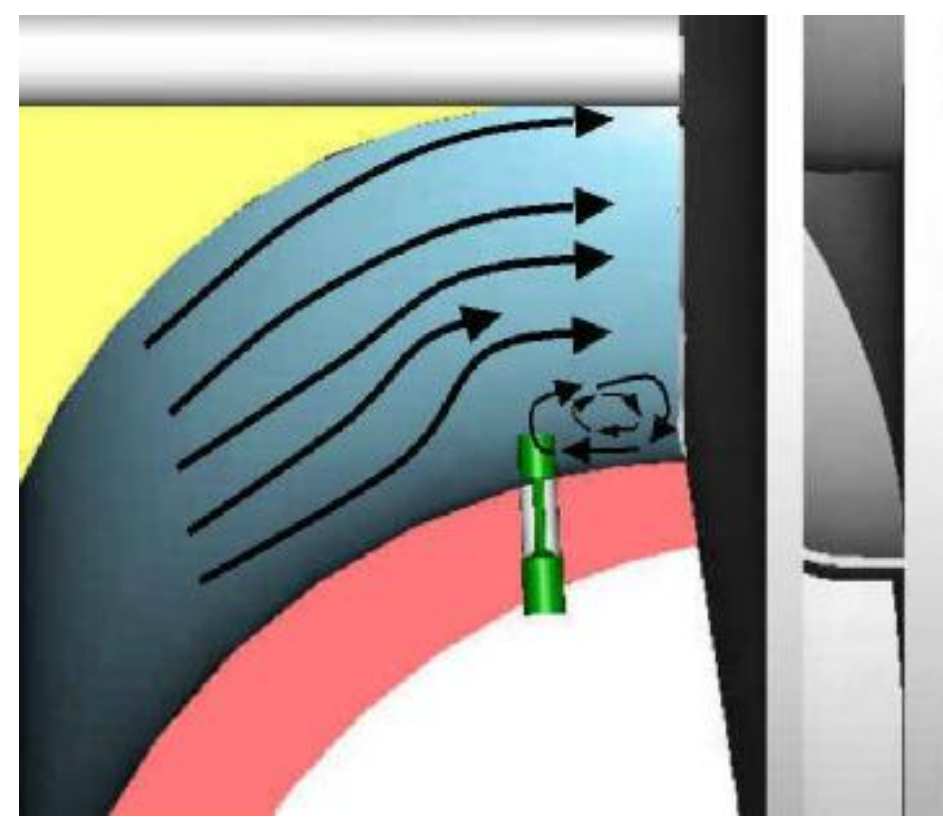

Figure 9. Diagram of Flow Vectors at a Near-Surge Condition Showing Recirculation Just at the Drag Probe.

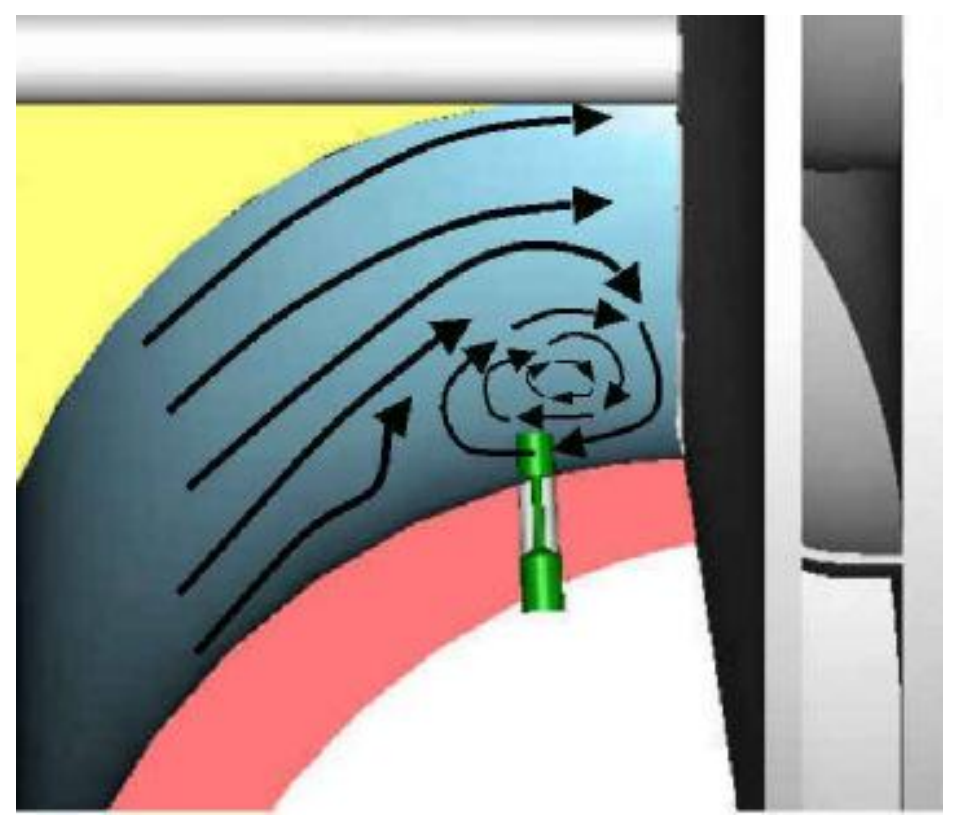

Figure 10. Diagram of Flow Vectors at a Surge Flow Condition Showing a Large Recirculation Zone.

\subsection{THEORIES AND FACTORS THAT AFFECT SURGE PRECURSORS}

There are a number of theories that apply to the performance and operation of centrifugal compressors; however, none of these has been entirely satisfactory in terms of predicting or controlling surge. According to stability theory for a compressor in a pipeline system, surge 
should occur when the slope of the compressor head vs. flow curve becomes zero. However, in practice, compressors in some installations reach surge while the head curve is still (negative) rising to the left and, in other cases, compressors operate satisfactorily prior to surge even with a falling head with lower flow (positive slope). Another concept that is not supported by data or field results is that as surge is approached, a compressor experiences an increase in vibration, pulsation, and noise. It has been found that although some field units experience vibration and pulsation symptoms at lower flows, a significant number of operating units display no increase or change in vibration, pulsation, or noise prior to surge. For a portion of installed pipeline compressors, surge is a suddenly occurring event with no apparent warnings. It can be shown that the vibration, pulsation, noise, and rough operations that are sometimes associated with nearsurge conditions are a result of off-design flow angles and, in some cases, stall conditions within a compressor at low flow. These rough operations, vibrations, pulsation, etc., are associated with other low-flow behaviors, such as stall within a compressor, but are not a fundamental indication of approaching surge.

One theory or explanation of pre-surge behavior that does have merit is that as the flow through an impeller is reduced below its design flow coefficient or design capacity, which is a function of inlet area and rotational speed, more flow enters the impeller than can leave the discharge of the impeller (due to flow restrictions and head rise). Therefore, at a low-flow relative to the impeller capacity, some flow exits the suction side of the impeller in the reverse direction. What happens to this recirculating flow in the inlet passage of the impeller is a part of the underlying behavior behind this research effort and forms a precursor for surge. Based on this theory, the flow coefficient, which is a nondimensional volumetric inlet flow, should control when the flow recirculation develops and when surge occurs.

Also, based on the above explanation, the nondimensional location of the surge probe, in terms of distance from the impeller and height inward from the outer wall, should have a large effect on the flow condition and signal magnitude at which the flow recirculation is identified by the sensor. The details of the relationship between probe location (nondimensional) and the nature of the pre-surge recirculation signal are still being worked out. Table 1, which follows, identifies the pre-surge and surge flow coefficients, the distance from the impeller, and the height of the probe in the channel for each of the laboratory machines from which there is data, and for the planned field test compressor. The difference between the flow coefficient at which presurge is indicated and the flow coefficient at which surge occurs is the range of flow over which a control signal is available to prevent surge and avoid excess recycling.

The decrease in flow coefficient for the small original test compressor, $17.4 \%$ and for last year's first laboratory compressor, $20.3 \%$, are typical of the increase in operating range that can be expected using this type of surge controller. The increase in operating range indicated for the second laboratory compressor, $35.5 \%$, as indicated by the difference between the pre-surge and the surge condition flow coefficient, is most likely larger than for typical pipeline compressors. The reasons that the second laboratory compressor has a large increase in operating range include the estimate surge line may be at a higher flow than normal, the probe location and pre-surge signal were unusually good, and the general nature of the compressor. It should be noted that the flow coefficients for the first laboratory compressor are much smaller than for the other compressors, which indicates a smaller flow capacity per unit speed for this high pressure ratio 
compressor than for the other pipeline style machines. The less pipeline like flow coefficient and the narrow inlet passage may have contributed to the small pre-surge signal in this first laboratory compressor; however, the main reason for the lack of a strong pre-surge signal is the large nondimensional distance of the probe from the compressor impeller.

The distance that the probe is from the impeller is given as a fraction of the inlet passage height or inlet area radius. Thus, if the passage height or radius of the impeller inlet (not including the hub) is 3 inches and the center of the probe was 0.75 inches from the impeller face, the probe distance would be at the 0.25 location in terms of the inlet passage size. The height or maximum distance that the probe is out from the wall is also normalized by the inlet passage size or flow area radius. Thus, if the probe extends out from the inlet wall by 0.5 inches in the above 3 -inch inlet radius example, the wall height of the probe is 0.167 . In general, the closer the probe is to the impeller in nondimensional units, the sooner and stronger the expected recirculation flow signal. The effect of the nondimensional height from the wall is not as easily determined, but will affect the overall magnitude of the pre-surge signal and will influence the point at which the drag force changes from positive to negative. The higher the drag probes above the outer wall of the inlet passage, the greater the overall flow signals. However, since the recirculating flow starts as a small region near the wall, the greater the height of the probe above the wall, the more likely it is that the reversal of flow will be observed later in the pre-surge development. Table 1 summarizes the flow coefficient, pre-surge and surge, and nondimensional distance and height of the sensor for the original small laboratory compressor, the first and second laboratory compressor in this research program, and the compressor in which a field test is planned.

Table 1. Nondimensional Parameter of Flow Coefficient and Probe Location for Test Compressors.

\begin{tabular}{|c|c|c|c|c|}
\hline Compressor & $\begin{array}{c}\text { Flow Coeff. Pre- } \\
\text { Surge }\end{array}$ & $\begin{array}{c}\text { Flow Coeff. } \\
\text { Surge }\end{array}$ & Probe Distance & Probe Height \\
\hline Small Original & 0.712 & 0.588 & $0.35^{*}$ & 0.22 \\
\hline First Lab. & 0.153 & 0.122 & 1.15 & 0.43 \\
\hline Second Lab. & 0.670 & 0.432 & 0.31 & 0.37 \\
\hline Planned Field & 0.554 & ---- & 0.64 & 0.21 \\
\hline
\end{tabular}

${ }^{*}$ Effective sensing distance of the bi-directional pitot probe.

\subsection{FUTURE TESTING AND EXPECTED BENEFITS}

The next test that is planned is to verify this pre-surge detection in a full-size field compressor. The preparations have been made in that the probes have been designed, built, bench-tested, and installed. Photographs of a typical small drag probe surge detector and of the pipeline compressor installation are shown in Figure 10. Two large drag probes were installed as redundant sensors for the field test, although only one of these reliable probes is necessary as a surge controller. The surge probes themselves have been in place immediately in front of the impeller for several months of operation. The objective of the field test will be to verify sensing of the pre-surge flow pattern and that the probe positions and sensitivity are adequate. Some issues concerning the probe wiring and operational demands have delayed the field testing, but have been resolved. The field test will take place as soon as the compressor becomes operationally available. 


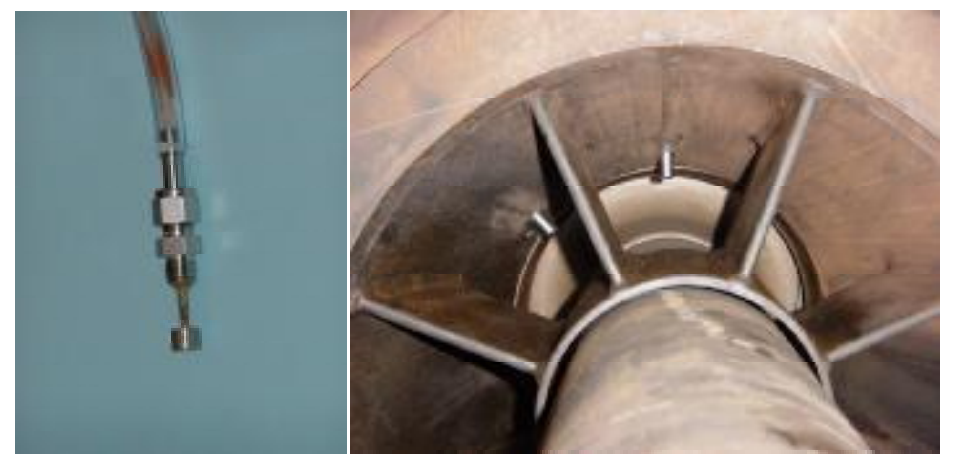

Figure 11. Photographs of a Small Typical Laboratory Surge Sensor Drag Probe and the Installation of Two Surge Sensor Probes in Field Compressor Ready for Testing.

The benefits of the test data that has been collected and presented above are that an active surge controller based on fundamental indications of approaching surge should be developable from the above types of signals. The resulting controller will have a range of pre-surge flows over which the compressor can be controlled and should have a wider safe operating range than without this type of pre-surge sensing. The internal sensing of pre-surge flow changes by a rugged drag probe provides a direct indication of approaching surge and an improved method for controlling centrifugal compressors to avoid surge and excess recycling of flow. 


\section{CONCLUSIONS}

The following conclusions can be drawn from the test results and evaluations of the presurge signals found during this reporting period:

1. Surge is a potentially damaging flow instability that limits the low-flow operation of centrifugal compressors and is usually avoided by recycling flow to maintain flow above some arbitrary surge margin. This can be wasteful when more flow is recycled than necessary and is costly in terms of energy and fuel when the compressor operation is maintained well above near-surge conditions at which the compressor could operate satisfactorily.

2. Early GMRC research identified a flow recirculation along the outer wall of a centrifugal compressor inlet as a probable precursor for surge and a potential control signal. In addition, it was found that most other signals, including vibration and pulsation, are NOT reliable indicators of approaching surge.

3. A drag probe is a suitable type of sensor to detect the changes in impeller inlet flow as surge approaches, because it is rugged, compatible with the internal compressor environment, sensitive to flow direction and magnitude changes, and sufficiently fast to respond.

4. Theoretical considerations not only support the recirculating flow cell development, but also indicate the importance of position of the surge detection probes relative to the impeller. Based on the original and the second laboratory compressor tests being more successful than the first laboratory compressor test, data shows that the drag probe should be between approximately 0.30 and 0.67 inlet passage heights from the impeller face and have a maximum height above the wall of approximately 0.20 to 0.35 times the inlet passage height. A sensing probe should not be over one inlet passage height from the face of the impeller.

5. The flow changes along the outer wall of a centrifugal compressor inlet do produce a recirculating flow cell as surge approaches, which reduces and then reverses the axial flow-induced strain on a drag probe and also causes an increase in the tangential strain due to a tangential flow component.

6. The pre-surge changes in a compressor's inlet flow pattern and the resulting changes in drag probe strain signals are repeatable at different compressor speeds and operating conditions, and at different rates of approach to surge. These changes occur at consistent flow coefficient values for a single machine, but occur for many different machines in such a way that they can be used as a surge control and avoidance signal. 


\section{REFERENCES}

1. McKee, R.J. and Deffenbaugh, D.M., "Increased Flexibility of Turbo-Compressors in Natural Gas Transmission Through Direct Surge Control," SwRI Project 18.04990, DOE Contract Award No. DE-FC26-01NT41163, Annual Technical Progress Report, October 2001 - April 2003.

2. McKee, R.J. and Deffenbaugh, D.M., "Factors That Affect Surge Precursors in Centrifugal Compressors," presented at GMRC Gas Machinery Conference, Salt Lake City, Utah, October 6-8, 2003. 